\title{
Enostosis of Clavicle Causing Severe Dyspnea by Compressing the Trachea Externally: Case Report
}

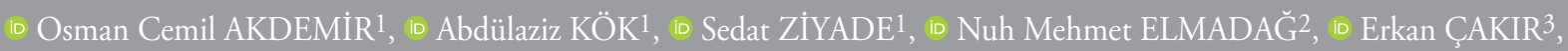

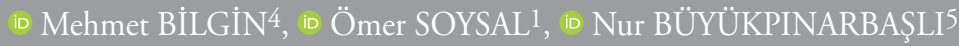

${ }^{1}$ Bezmialem Vakıf University Faculty of Medicine, Deparment of Thoracic Surgery, İstanbul, Turkey

2Bezmialem Vakıf University Faculty of Medicine, Department of Orthopedics, İstanbul, Turkey

${ }^{3}$ Bezmialem Vakıf University Faculty of Medicine, Deparment of Child Chest Diseases, İstanbul, Turkey

${ }^{4}$ Bezmialem Vakıf University Faculty of Medicine, Deparment of Radiological, İstanbul, Turkey

5Bezmialem Vakıf University Faculty of Medicine, Deparment of Pathology, İstanbul, Turkey

\begin{abstract}
Clavicle is the bone that forms anterior border of shoulder arch. It lies on anterosuperior of thorax with first rib. Clavicle is very near to major vascular structures, brachial plexus, esophagus and trachea at thoracic inlet. Because of this, clavicular lesions fractures and sternoclavicular dislocations -especially posterior dislocations- may cause symptoms due to compressing symptoms due to these structures. In this article we present a case with enostosis of clavicle causing respiratory failure by compressing on trachea.
\end{abstract}

Keywords: Clavicle, enostosis, repiratory failure

\section{Introduction}

Clavicle is the bone that forms anterior border of shoulder arch. It lies on anterosuperior of thorax with first rib (1). At the upper thoracic inlet, around sternoclavicular joints area, both of clavicle are anotamically near with subclavian arteries and veins, both brachial plexuses esophagus and trachea, both carotid arteries and jugulary veins. Because of nearness to major vascular structures, brachial plexus, esophagus and trachea at thoracic inlet clavicle lessions, fractures and sternoclavicular dislocations -especially posterior dislocations- causes symptoms due to these structures being affected

\section{Case Report}

A six-year-old girl was referred to pediatric pulmonology outpatient clinic with complaint of irritative cough and dyspnea that continues for a long time in spite of medical treatment. Three months before, she was hospitalized in intensive care unit because of occurrence of respiratory failure after a caughing crisis. Flexible bronchoscopy revealed a pulsatile externally compressing lesion on anterior wall of trachea (Figure 1).

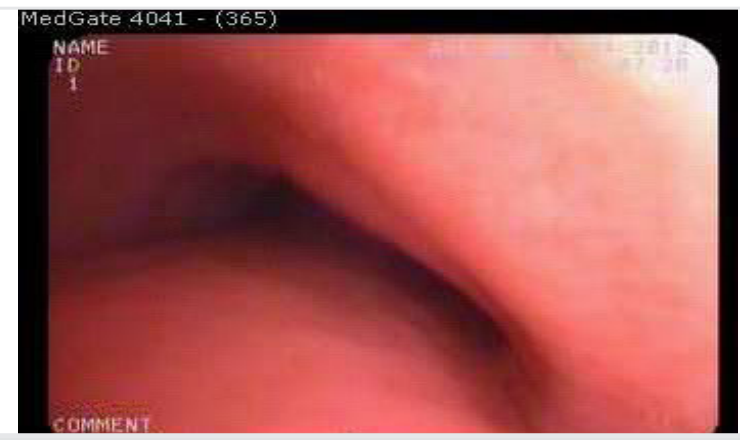

Figure 1. Pulsatile externally compression narrowing the lumen of trachea on right anterolateral

Address for Correspondence: Sedat ZIYADE, Bezmialem Vakıf University Faculty of Medicine, Deparment of Thoracic Surgery, ìstanbul, Turkey

Phone: +90 45317 00- 2353 E-mail: datziyade@gmail.com ORCID ID: orcid.org/0000-0002-9549-0633

Cite this article as: Akdemir OC, Kök A, Ziyade S, Elmadağ NM, Çakır E, Bilgin M, Soysal Ö,

Büyükpınarbaşıı N. Enostosis of Clavicle Causing Severe Dyspnea by Compressing the Trachea Externally: Case Report. Bezmialem Science 2019;7(2):167-9. 
Thorax CT angiography revealed a lession protruding into mediastinum which was thought to behyperthrophy of the bone or osteophyte. It was below the right subclavian artery and was compressing on trachea at the junction of right common carotid artery and right subclavian artery (Figure 2).

Mediastinal vascular structures were normal. On physical examination, thoracic inlet was close-fitting because of wide interclavicular ligament. It was thought that pulsatile, external compression seen at flexible bronchoscopy was due to the lession of clavicle, and operation was decided. Clavicle was reached by an incision started at upper point of sternum through laterally to the medial head of clavicle. Approximatelly, $1 \mathrm{~cm}$ long and 4-5 $\mathrm{mm}$ wide, hard and tight interclavicular ligament was seen and

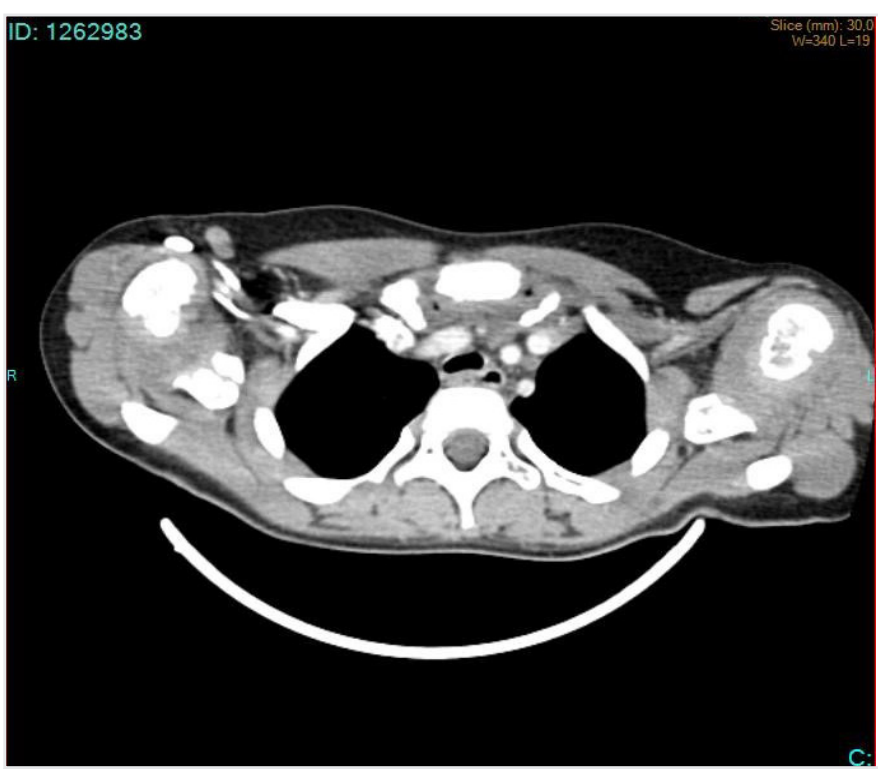

Figure 2. Preoperative thorax CT angiography: Hypertrophic osseosis lession on the head of right clavicle compressing on vascular structures and the trachea

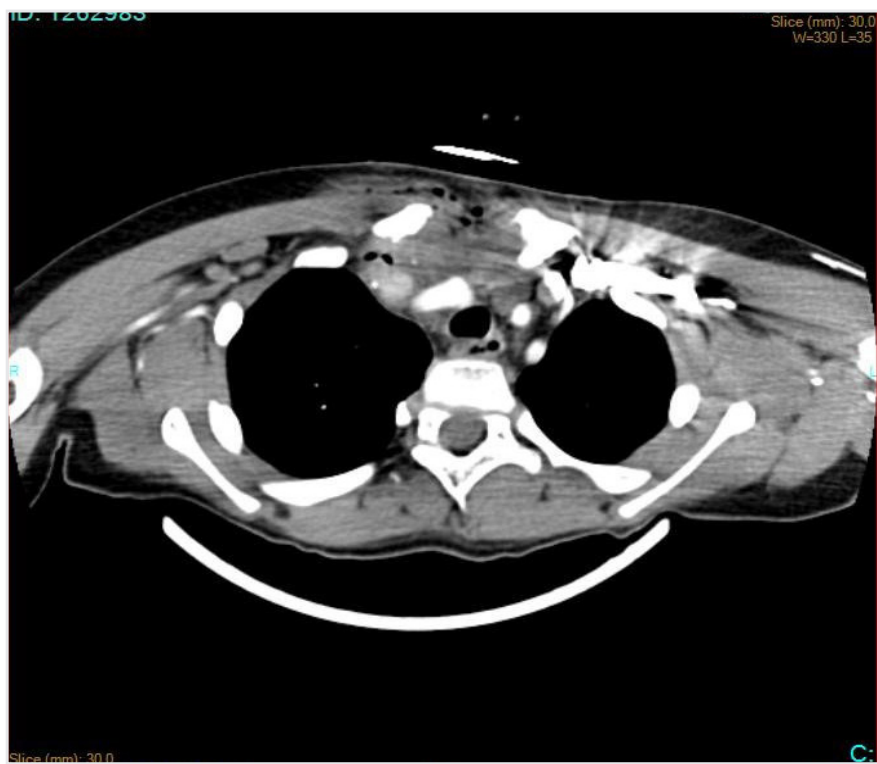

Figure 3. Postoperative thorax CT: Lession excised, Shape of the trachea and vascular structures are circle excised. Head of right clavicle was explored by opening the periost (Figures 4-5).

Hypertrophic tissue protruding posteriorly was excised. Mediastinum was controlled by finger disection as it was relaxed. Procedure was finished after placing a minivac drain into the disection area. At postoperative CT, compression on mediastinal structures was disappeared (Figure 3). The patient was discharged on the first postoperative day. Pathology was reported as enostosis (bone island). The patient was seen on the postoperative sixth month and she was having neither cough nor dyspnea.

\section{Discussion}

Posterior dislocations may cause some symptoms due to compression of head of clavicle on contiguous structures and injuries or lacerations may occur due to direct effect or trauma. In the literature, there have been cases of injury or laceration of innominate vein, innominate artery, esophagus, trachea, brachial plexus, and even vena cava or compression on vena cava because of posterior dislocation and cases having symptoms due to compression of tumours of head of clavicle (2-9). We did not

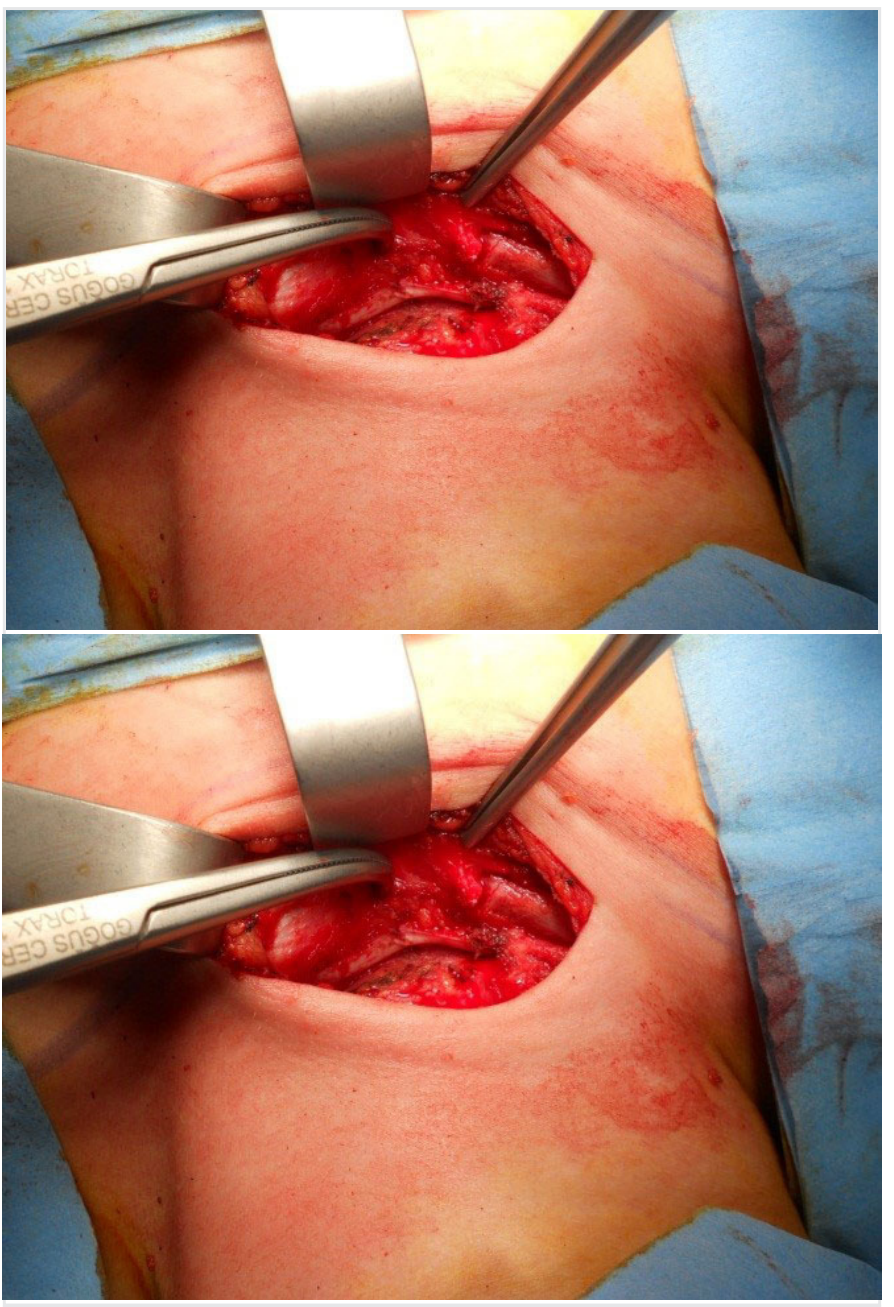

Figures 4-5. Thick interclavicular ligament and view after interclavicular ligament excised and clavicle was turned subperiostally 
encounter such a case withenositosis in the literature. Pathologies on this area may have crucial risks. Until now, mortality because of posterior dislocation of clavicle due to injury was reported in five cases (10). In this article, we aimed to emphasize the importance of pathologies in the head of clavicle in cases with external compression to trachea causing respiratory failure.

Bone Iisland (enositosis) is a focus of compact bone located in cancellous bone. This is a benign entity that is rarely symptomatic and that is usually found incidentally in radiological studies. Symptoms are pain and protuberance due to enlargement of the lesion. In our case, in physical examination there was no protuberance but it was determined that thoracic inlet was close-fitting because of wide interclavicular ligament. In radiological examination, there was a lesion on the head of right clavicle protruding to mediastinum which was considered as hyperthrophy or osteophyte. Under this lesion, right subclavian artery was bending to posterior and the lesion was compressing the trachea at the junction of right common carotid artery and right subclavian artery.

Tracheal stenosis caused by external compression may cause recurrent pulmonary infections, symptoms like wheezing, chronic cough and even respiratory failure. Diseases with vascular abnormalities, aneurysms, mediastinal masses, lymphadenopathies may cause tracheal stenosis. Lesions on the head of clavicle are extremely rare. In differential diagnosis of this clinical situations, lesions compressing to trachea externally, and foreign body aspirations must be considered. For diagnosis, flexible bronchoscopy and thorax CT with intravenous contrast must be used. So, that localization and severity of stenosis, and lesion causing stenosis may be determined and treatment may be planned.

In cases with external compression to trachea causing respiratory failure, pathologies of the head of clavicle must be kept in mind. Bone island is one of them. In treatment, removing the compression on vascular structures or trachea by excising the head of clavicle partially may be performed and results are satisfactory in terms of symptoms.

\section{Ethics}

\section{Informed Consent:}

Peer Review: Externally peer-reviewed.

\section{Authorship Contributions}

Concept: S.Z., O.C.A., Ö.S., Design: N.M.E., E.Ç., N.B., Data Collection or Processing: Ö.S., M.B., A.K., Analysis or Interpretation: M.B., N.B., N.M.E., Literature Search: O.C.A., Writing: S.Z., O.C.A., Ö.S.

Conflict of Interest: No conflict of interest was declared by the authors.

Financial Disclosure: The authors declared that this study received no financial support.

\section{References}

1. Gray, Henry. Anatomy of the Human Body. Philadelphia: Lea\&Febriger, 1918; Bartelby.com, 2000. www.bartelby.com/107/.

2. Carbone P, Rose M, O’Daniel JA, Doukas WC, O’Toole RV, Andersen RC. Posterior Remodeling of Medial Clavicle Causing Superior Vena Cava Impingement. Am J Orthop (Belle Mead NJ) 2011;40:297-300.

3. Fenig M, Lowman R, Thompson BP, Shayne PH. Fatal posterior sternoclavicular joint dislocation due to occult trauma. Am J Emerg Med 2010;28:385.e5-8.

4. Mollano AV, Hagy ML, Jones KB, Buckwalter JA. Unusual osteochondroma of the medial part of the clavicle causing subclavian vein thrombosis and brachial plexopathy. J Bone Joint Surg Am 2004;86-A(12):2747-50.

5. Gangahar DM, Flogaites T. Retrosternal dislocation of the clavicle producing thoracic outlet syndrome. J Trauma 1978;18:369-72.

6. Nakayama E, Tanaka T, Noguchi T, Yasuda J, Terada Y. Tracheal stenosis caused by retrosternal dislocation of the right clavicle. Ann Thorac Surg 2007;83:685-7.

7. Ono K, Inagawa H, Kiyota K, Terada $T$, Suzuki S, Maekawa K. Maekawa. Posterior dislocation of the sternoclavicular joint with obstruction of the innominate vein: Case report. J Trauma 1998;44:381-3.

8. Sykes JA, Ezetendu C, Sivitz A, Lee J Jr, Desai H, Norton K, et al. Posterior dislocation of sternoclavicular joint encroaching on ipsilateral vessels in 2 pediatric patients. Pediatr Emerg Care 2011;27:327-30.

9. Wasylenko MJ, Busse EF. Posterior dislocation of the clavicle causing fatal tracheoesophageal fistula. Can J Surg 1981;24:626-7.

10. Garg S, Alshameeri ZA, Wallace WA. Posterior sternoclavicular joint dislocation in a child: a case report with review of literature. J Shoulder Elbow Surg 2012;21:e11-6. 